\title{
Treating the Pain of Osteoarthritis - Where Do We Go from Here?
}

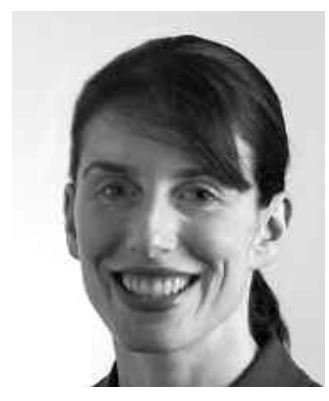

Pain is the overriding clinical issue in osteoarthritis (OA). Pain is what motivates patients to seek medical care, and pain is what drives patients to have total joint replacement surgery ${ }^{1}$. Although rheumatologists deal with OA patients and their pain on a daily basis, we are often ineffective in our attempts to address what many consider a very straightforward complaint. This may be because, as Mease and colleagues describe in their article in this issue of The Journal ${ }^{2}$, the mechanisms underlying the pain of $\mathrm{OA}$ are surprisingly complex.

OA pain has traditionally been viewed as peripherally mediated nociceptive pain. Noxious stimuli from the damaged joint stimulate peripheral nerve endings, triggering the ascending and descending neuronal pathways, which results in pain perception. However, this model provides only a starting point for understanding the pathophysiology even the basic relationship between bony changes and pain is unclear. For example, bone marrow lesions (BML), which represent a heterogeneous group of morphologic changes in the subchondral bone, are readily seen on magnetic resonance imaging. These lesions contain peripheral nociceptors, and many investigators have shown a clear correlation between $\mathrm{BML}$ and pain in patients with $\mathrm{OA}^{3}$. However, significant BML can be seen in pain-free subjects without OA, and intriguingly, the presence of BML predicts the development of pain in these patients ${ }^{4}$.

There is clearly more to OA pain than local osseous damage. Peripheral nociceptors are located not only on periosteum and subchondral bone, but also on ligaments, the synovial capsule, and menisci - soft tissue structures that comprise the "joint organ." In fact, as Mease and colleagues point out, cartilage itself is aneural, and therefore does not normally perceive noxious stimuli. This underscores why it is important to move beyond a "cartilage-centric" view of OA to optimize pain management. For example, as might be expected given the poor correlation between radiographic findings and pain severity in patients with OA, preoperative radiographic stage is not associated with clinical outcomes one year after total hip replacement ${ }^{5}$. However, the degree of joint space narrowing remains a major factor influencing orthopedic surgeons' decision to recommend joint replacement in patients with $\mathrm{OA}^{6}$. This suggests that innovative pain measurement tools, such as the I COAP (Intermittent and Constant Osteoarthritis Pain Questionnaire), rather than measures of cartilage loss, are needed to help determine the optimal timing of arthroplasty - the definitive treatment for painful $\mathrm{OA}^{7}$.

In patients with $\mathrm{OA}$, it is recognized that low-grade synovial inflammation is often present and correlates with pain severity $^{8}$. Indeed, inflammation may be the crucial link between local noxious stimuli and recruitment of centrally mediated pathways. As Mease and colleagues point out, when inflammatory mediators, such as cytokines, chemokines, and matrix metalloproteinases, are released intraarticularly from damaged tissue, they can modulate both central and peripheral nociceptors.

Interestingly, synovial inflammation appears to correlate with pain, even in nonarthritic joints. A recent study evaluated patients without radiographic OA undergoing arthroscopy for acute meniscal injuries. These patients were found to have synovial inflammation that correlated with knee pain. In addition, not only did these patients have a unique chemokine signature, but almost all had intraoperative evidence of early $\mathrm{OA}^{9}$. It is intriguing to speculate that chemokines or other markers of inflammation may be both biomarkers for early $\mathrm{OA}$ and potential therapeutic targets for pain relief.

One such promising therapeutic target for the treatment of OA pain is nerve growth factor (NGF). NGF is a neurotrophin, which is released from inflamed tissue and sensitizes peripheral nociceptors. Animal models have shown that by blocking the action of NGF with a soluble receptor or monoclonal antibody, pain can be significantly reduced ${ }^{10,11}$. Human trials of tanezumab, a humanized monoclonal anti-

See Pain mechanisms in OA, page 1546

Personal non-commercial use only. The Journal of Rheumatology Copyright (c) 2011. All rights reserved. 
body against NGF, showed significant reduction in pain and improvement in function in patients with knee $\mathrm{OA}^{12}$. Although the development of this particular monoclonal antibody has been stopped due to accelerated rates of OA, the clinical efficacy of an innovative targeted therapy for $\mathrm{OA}$ is encouraging.

Most recommended treatments for OA pain target elements of the peripheral nociceptive nervous system (e.g., weight loss and physical therapy decrease peripheral stimuli), or aim to decrease inflammation [e.g., intraarticular steroids and nonsteroidal antiinflammatory drugs (NSAID)]. However, as the authors highlight, the peripheral nociceptive/inflammatory model of pain appears to be an incomplete explanation for the universe of $\mathrm{OA}$ pain. Unremitting pain from an osteoarthritic joint may eventually lead to central sensitization, manifesting as a hyperreponsiveness to nociceptive stimuli, a lowering of the pain threshold, and pain with a distinctive neuropathic quality. In fact, up to a quarter of patients with knee OA have complaints of neuropathic-type pain ${ }^{13}$. Clinical studies also support this hypothesis. OA patients have been shown to have alterations in the central processing of pain, as evidenced by increased sensitivity to pressure stimuli at multiple anatomic sites ${ }^{14}$.

Central nervous system sensitization may explain why so many patients with OA have residual pain that is not effectively treated with drugs targeting peripheral or inflammatory pathways. Epidemiologic data provide evidence in support of this "treatment gap." The use of strong opioids for the treatment of chronic musculoskeletal pain in the US quadrupled between 1980 and 2000, during which time the prevalence of OA also rose dramatically ${ }^{15,16}$. Opioids and narcotic analgesics, although effective short-term therapies, are not viable for the longterm treatment of most patients with chronic OA pain. This increase in the use of narcotics points to a significant unmet need for effective pain control in these patients. As discussed by Mease, et al, medications developed for other diseases (e.g., antiepileptics and antidepressants) have serendipitously been found to have centrally mediated pain effects. Although preliminary clinical trials of antidepressants have been especially promising, there need to be much larger, longterm studies to assess the durability and safety of centrally acting pain medication in OA patients.

Central nervous system sensitization may also explain why up to $8 \%$ of primary total hip replacement patients complain of moderate to severe pain 2 years postoperative$1 y^{17}$. Why does physically removing the pathologic joint not result in resolution of pain? These "clinical failures" patients with no obvious implant or mechanical derangement but ongoing pain - are extremely frustrating for both physician and patient. Perhaps if the original "noxious stimuli" are not removed or controlled early enough in the course of OA, the patient's pain thresholds will be irrevoca- bly altered. Again, much research still needs to be done to determine if such a "window of opportunity" exists. This would have tremendous implications for both the timing and intensity of medical and surgical interventions for OA pain.

Our inability to adequately treat OA pain may not only be uncomfortable for our patients, but it may also be fatal. All-cause mortality is increased in patients with knee and hip $\mathrm{OA}^{18}$. Rates of death in these patients are significantly associated with walking disability, diabetes, and cardiovascular disease ${ }^{18}$. Pain is a major disincentive to walking and other physical activity, and thus poor pain control prevents optimal nonmedical management of these significant comorbid conditions. In addition, perhaps we need to rethink the use of NSAID as our "go-to" medication for OA. The vast majority of all NSAID are prescribed for pain, and are certainly the mainstay of OA therapy. Both the American College of Rheumatology guidelines (soon to be updated) and OARSI Guidelines for the management of OA feature NSAID prominently ${ }^{19,20}$. However, NSAID have been shown to be associated with clinically important increases in the risk of cardiovascular death - the predominant cause of death in patients with knee and hip $\mathrm{OA}^{18,21}$. For an individual patient with OA, the "harm reduction" in choosing or avoiding NSAID is very difficult to quantify. The development of OA medications that specifically target central or peripheral neuronal pathways may be "NSAID-sparing," with the dual effect of improving pain control and potentially improving mortality.

Pain in OA remains a significantly undertreated problem. This overview reminds us that pain is complex, and how important ongoing research into targeted therapies will be to ensure the best care for our patients.

LISA MANDL, MD, MPH,

Assistant Research Professor of Medicine, Department of Rheumatology, Weill Cornell Medical College, Hospital for Special Surgery, 535 East 70th Street, New York, NY 10021, USA

Address correspondence to Dr.Mandl; E-mail: MandlL@hss.edu

\section{ACKNOWLEDGMENT}

Thanks to Dr. Steven Goldring for his helpful review of the manuscript.

\section{REFERENCES}

1. Altman RD, Hochberg M, Murphy WA Jr, Wolfe F, Lequesne M. Atlas of individual radiographic features in osteoarthritis. Osteoarthritis Cartilage 1995;3 Suppl A:3-70.

2. Mease PJ, Hanna S, Frakes EP, Altman RD. Pain mechanisms in osteoarthritis: understanding the role of central pain and current approaches to its treatment. J Rheumatol 2011;38:1546-51.

3. Lo GH, McAlindon TE, Niu J, Zhang Y, Beals C, Dabrowski C, et al. Bone marrow lesions and joint effusion are strongly and independently associated with weight-bearing pain in knee osteoarthritis: data from the osteoarthritis initiative. Osteoarthritis Cartilage 2009; 17:1562-9. 
4. Davies-Tuck ML, Wluka AE, Wang Y, English DR, Giles GG, Cicuttini F. The natural history of bone marrow lesions in community-based adults with no clinical knee osteoarthritis. Ann Rheum Dis 2009;68:904-8.

5. Nilsdotter AK, Aurell Y, Siosteen AK, Lohmander LS, Roos HP. Radiographic stage of osteoarthritis or sex of the patient does not predict one year outcome after total hip arthroplasty. Ann Rheum Dis 2001;60:228-32.

6. Gossec L, Paternotte S, Maillefert JF, Combescure C, Conaghan PG, Davis AM, et al. The role of pain and functional impairment in the decision to recommend total joint replacement in hip and knee osteoarthritis: an international cross-sectional study of 1909 patients. Report of the OARSI-OMERACT Task Force on total joint replacement. Osteoarthritis Cartilage 2011;19:147-54.

7. Hawker GA, Davis AM, French MR, Cibere J, Jordan JM, March L, et al. Development and preliminary psychometric testing of a new OA pain measure - an OARSI/OMERACT initiative. Osteoarthritis Cartilage 2008;16:409-14

8. Baker K, Grainger A, Niu J, Clancy M, Guermazi A, Crema M, et al. Relation of synovitis to knee pain using contrast-enhanced MRIs. Ann Rheum Dis 2010;69:1779-83.

9. Scanzello CR, McKeon B, Swaim BH, DiCarlo E, Asomugha EU, Kanda V, et al. Synovial inflammation in patients undergoing arthroscopic meniscectomy: molecular characterization and relationship to symptoms. Arthritis Rheum 2011;63:391-400.

10. McNamee KE, Burleigh A, Gompels LL, Feldmann M, Allen SJ, Williams RO, et al. Treatment of murine osteoarthritis with TrkAd5 reveals a pivotal role for nerve growth factor in non-inflammatory joint pain. Pain 2010;149:386-92.

11. Koewler NJ, Freeman KT, Buus RJ, Herrera MB, Jimenez-Andrade JM, Ghilardi JR, et al. Effects of a monoclonal antibody raised against nerve growth factor on skeletal pain and bone healing after fracture of the C57BL/6J mouse femur. J Bone Miner Res 2007;22:1732-42.

12. Lane NE, Schnitzer TJ, Birbara CA, Mokhtarani M, Shelton DL, Smith MD, et al. Tanezumab for the treatment of pain from osteoarthritis of the knee. N Engl J Med 2010;363:1521-31.
13. Hochman JR, Gagliese L, Davis AM, Hawker GA. Neuropathic pain symptoms in a community knee OA cohort. Osteoarthritis Cartilage 2011;19:647-54.

14. Lee YC, Lu B, Bathon JM, Haythornthwaite JA, Smith MT, Page $\mathrm{GG}$, et al. Pain sensitivity and pain reactivity in osteoarthritis. Arthritis Care Res 2010 Oct 18. [Epub ahead of print]

15. Caudill-Slosberg MA, Schwartz LM, Woloshin S. Office visits and analgesic prescriptions for musculoskeletal pain in US: 1980 vs. 2000. Pain 2004;109:514-9.

16. Lawrence RC, Helmick CG, Arnett FC, Deyo RA, Felson DT, Giannini EH, et al. Estimates of the prevalence of arthritis and selected musculoskeletal disorders in the United States. Arthritis Rheum 1998;41:778-99.

17. Singh JA, O'Byrne MM, Harmsen WS, Lewallen DG. Predictors of moderate-severe functional limitation 2 and 5 years after revision total knee arthroplasty. J Arthroplasty 2010;25:1091-5; e1-4.

18. Nuesch E, Dieppe P, Reichenbach S, Williams S, Iff S, Juni P. All cause and disease specific mortality in patients with knee or hip osteoarthritis: population based cohort study. BMJ 2011;342:d1165

19. Recommendations for the medical management of osteoarthritis of the hip and knee: 2000 update. American College of Rheumatology Subcommittee on Osteoarthritis Guidelines. Arthritis Rheum 2000;43:1905-15.

20. Zhang W, Nuki G, Moskowitz RW, Abramson S, Altman RD, Arden $\mathrm{NK}$, et al. OARSI recommendations for the management of hip and knee osteoarthritis: part III: Changes in evidence following systematic cumulative update of research published through January 2009. Osteoarthritis Cartilage 2010;18:476-99.

21. Trelle S, Reichenbach S, Wandel S, Hildebrand P, Tschannen B, Villiger PM, et al. Cardiovascular safety of non-steroidal anti-inflammatory drugs: network meta-analysis. BMJ 2011;342:c7086.

J Rheumatol 2011;38:1535-7; doi:10.3899/jrheum.110671 